\title{
Germanica
}

\section{En höst kommer - Un inédit de Stig Dagerman}

\section{Georges Ueberschlag}

\section{CpenEdition}

Journals

Édition électronique

URL : http://journals.openedition.org/germanica/1504

DOI : 10.4000/germanica.1504

ISSN : 2107-0784

\section{Éditeur}

Université de Lille

\section{Édition imprimée}

Date de publication : 1 juin 1993

Pagination : 199-201

ISSN : 0984-2632

\section{Référence électronique}

Georges Ueberschlag, "En höst kommer - Un inédit de Stig Dagerman», Germanica [En ligne], 12 | 1993 mis en ligne le 06 juillet 2012, consulté le 06 octobre 2020. URL : http://journals.openedition.org/ germanica/1504; DOI : https://doi.org/10.4000/germanica.1504

Ce document a été généré automatiquement le 6 octobre 2020.

() Tous droits réservés 


\title{
En höst kommer - Un inédit de Stig Dagerman
}

\author{
Georges Ueberschlag
}

1 Stig Dagerman a écrit la nouvelle que nous publions ci-dessous tout à fait au début de ses ambitions littéraires. Succombant, à l'âge de dix-huit ans, à la tentation de l'héroïsme gratuit, qui sied si bien à la jeunesse, il s'était inscrit au Club des Jeunesses anarcho-syndicalistes de Stockholm et avait déjà écrit quelques textes pour la revue Storm. Il s'était vite aperçu que, dans la lutte pour le bonheur universel, son arme la plus efficace ce serait la plume.

2 La nouvelle Un automne (titre suédois : En höst kommer), a été écrite en 1941. Elle est encore signée du premier patronyme de Dagerman, Stig Harald Jansson. En effet, ce n'est qu'en 1942, pour bien marquer le caractère irréversible de son engagement anarchiste, de l'homme nouveau qu'il revêt, que Stig prend la décision de changer de nom. Ce changement est officiellement enregistré en date du 27 février 1942. Stig Harald Jansson devient alors Stig Dagerman.

3 Le sens symbolique de ce nouveau patronyme, qui ne figurait guère encore dans le registre des noms suédois, est tout à fait clair. "Dager", c'est la lumière du jour naissant, l'espoir. Stig se veut donc l'homme de la lumière et de l'espoir.

4 Alors pourquoi ce titre de nouvelle: Un automne?

5 Ce texte, nourri de sombres pressentiments, ressemble par sa tonalité à celui d'une autre nouvelle que le jeune auteur de dix-huit ans venait de publier dans le numéro de Noël du Journal de l'Association des élèves de son lycée, sous le titre Le chien et son destin (nouvelle ne figurant pas dans l'édition des cuvres complètes de Stig Dagerman). Elle lui avait permis de remporter, fin 1941, le premier prix d'un concours littéraire pour les lycéens organisé par le journal Stockholms Tidningen.

6 Tout comme Le chien et son destin, la nouvelle Un automne présente, comme on le verra, toutes les caractéristiques d'une cuvre de jeunesse. En recherche.

7 Recherche d'un style se voulant cinglant et dépouillé, par son alignement obstiné de petites principales, style suggestif, saccadé comme un compte rendu, représentatif, par la rareté de l'adjectif, d'une humanité à bout de souffle. 
8 Recherche d'un sens à la vie, du bonheur impossible, et son expérience concrète au niveau de l'individu, qui en est l'infirmation à défaut d'en être la confirmation. Cri de révolte contre la guerre et appel à la vie, à l'amour qui sauve.

9 Texte un peu gauchement moralisateur, didactique, comme celui d'un prophète maladroit parlant en paraboles et en symboles.

10 L'auteur se penche sur l'envie de mourir qui saisit les hommes, qui le saisit lui-même à l'âge de dix-huit ans, et à laquelle il succombera treize ans plus tard, alors qu 'il faudrait être conscient de toutes les raisons qu'on a de vouloir vivre, de la nécessaire victoire du Bien.

11 L'arrière-plan de cette nouvelle, le vécu personnel, est tout à fait évident : l'expérience du foyer paternel où la communication est devenue impossible, l'attente perpétuelle d'un bonheur fuyant, les convois de militaires allemands qui ont traversé la Suède à cette époque de guerre comme une menace obscure.

12 Au thème de cette première nouvelle de Stig Dagerman répond, comme un écho lointain, celui de la dernière qu'il ait écrite, Quand on s'en va, publiée en décembre 1953, peu de mois avant sa mort, par la revue Vi. Exemple remarquable de continuité et de fidélité à lui-même dans la vie d'un auteur. Dans l'une et l'autre la quête du bonheur et de la vraie vie débouche sur du silence, le silence de la nuit.

13 Stig Dagerman avait proposé le texte de sa nouvelle En höst kommer en 1941 à la maison d'édition Bonnier de Stockholm, pour un numéro du Bonniers litterära magasin consacré à de jeunes débutants. On la lui avait renvoyée, avec le mot de regrets habituel, manquant singulièrement de flair. Bonnier ne sera jamais, malgré les tentatives ultérieures pour l'enrôler, le principal éditeur de Dagerman.

14 Celui-ci avait alors fait cadeau de son texte, en 1942, à Anne-Marie Götze, la jeune réfugiée anarchiste allemande, qui allait bientôt devenir sa femme. Elle vient de le mettre gracieusement à notre disposition. Qu'elle veuille bien trouver ici l'expression de la reconnaissance de notre revue. 